\title{
Verifying Dynamic Kano's Model to Support New Product/Service Development
}

\author{
Yuri Borgianni \\ Free University of Bozen-Bolzano, Faculty of Science and Technology (Italy) \\ yuri.borgianni@unibr.it
}

Received: February 2018

Accepted: May 2018

\begin{abstract}
:
Purpose: Although firms try to shorten time-to-market, the duration of product development projects might anyway jeopardize the assumptions made at the beginning of the design process. This includes the definition of product attributes for ensuring customer satisfaction, thus forecasting techniques could be worthwhile. Within Kano's method, trajectories of quality attributes have been identified and they can be potentially useful to the scope, but they have not been carefully verified.
\end{abstract}

Design/methodology/approach: The paper takes on the above verification challenge by exploring studies of customer satisfaction conducted by means of Kano's model regarding manifold industrial fields. The paper focuses on changes in the relevance of customer requirements reported in different contributions and analyses data statistically.

Findings: The dynamic trajectories outlined in Kano's model are partially confirmed and they are valuable in the mid-term to predict changes in customer preferences. The use of quantitative indicators portraying the extent of customer satisfaction and dissatisfaction leads to more reliable predictions.

Research limitations/implications: In order to use as many data as possible, information has been gathered from different industrial fields, which can exhibit different paces in changes of customer preferences.

Practical implications: The results benefit firms willing to have a clearer picture of customer main drivers for customer satisfaction at the time of market launch, although customer surveys are conducted at the beginning of product development projects.

Originality/value: The paper puts into question previous assumptions about modifications of customer preferences, which, however are just empirically supported and assesses how these can be exploited in a reliable way.

Keywords: Kano's theory, customer requirements, customer satisfaction, product design, dynamic preferences, forecasting

\section{To cite this article:}

Borgianni, Y. (2018). Verifying dynamic Kano's model to support new product/service development. Journal of Industrial Engineering and Management, 11(3), 569-587. https://doi.org/10.3926/jiem.2591 


\section{Introduction and Motivation of the Work}

Kano's theory of attractive quality (Kano, Seraku, Takahashi \& Tsuji, 1984) is an important reference in the field of quality management, as underlined by numerous recent research studies from this domain that have exploited its findings in both product and service domains, e.g. (Kim, Geum \& Park, 2017; Potra, Izvercian, Pugna \& Dahlgaard, 2017; Sohn, Woo \& Kim, 2017). A standard method originating from the theoretical fundamentals represents an effective approach to helping understand the potentiality of each customer requirement by emphasizing the asymmetric relationship between performance and perceived satisfaction. This is achieved by defining a specific category of quality attributes for each customer requirement according to its capability to excite and/or avoid severe dissatisfaction if unfulfilled. Details will be provided in Section 2.

The increasing role of Kano's method is well explained in the review paper authored by Witell, Löfgren and Dahlgaard (2013). The same source witnesses an ongoing explosion phase for the employment of the model and clarifies how we are likely on the verge of an explanatory research phase. The scholars address various theoretical and practical aspects requiring close investigation that include the lifecycle of quality attributes. Kano (2001) has outlined regularities in the dynamics of customer preferences and quality attributes, as widely discussed in (Löfgren, Witell \& Gustafsson, 2011). However, empirical validation of these dynamic mechanisms is still required and this justifies the call for more insightful understanding. It is worth highlighting that a better comprehension of the evolution of quality attributes would enable the prediction of the future relationship between fulfilled product/service requirements and displayed customer satisfaction. This can represent a great contribution in the field of product/service design especially with regard to those companies that carry out New Product Development (NPD) initiatives by entrusting the so-called Voice of the Customer (VoC). In these situations, customers play a fundamental decision-making role, being asked to provide feedback about new products or single characteristics. Changes in customer preferences are viable to invalidate the decisions made at the beginning of NPD tasks (Bacciotti, Borgianni, Cascini \& Rotini, 2016) especially when much time elapses from the project start to the market launch (Chong \& Chen, 2010); their effects can be already displayed during the supply chain phase (Marsillac \& Roh, 2014). As a result, it might happen that firms launch products in the market fulfilling customer requirements whose importance has been verified just during the product development process, as suggested by Figure 1.

Based on these premises, the paper strives to verify the possibility of forecasting customer preferences in the future, based on the constructs of Kano's model. In order to assess the role of time, the presented study neglected other factors that can potentially influence the difference of customer preferences resulting from distinct surveys (e.g. demographical factors of respondents). The prediction of customer preferences originates from statistical functions, which have been built by exploiting the dispersed material that is present in the literature. Indeed, several investigations have been carried out by means of Kano's model independently and without making any reference or comparisons with previous outcomes. The study overall examined the alteration of 176 product requirements and service attributes.

The paper is structured as follows. Section 2 recalls the fundamentals of Kano's theory and introduces the logic followed by dynamic Kano models. Section 3 presents the strategy followed by the present investigation in order to forecast the magnitude of dynamic phenomena. Section 4 presents the results of the empirical analysis. These outcomes are further commented in Section 5, which includes future activities and final remarks too.

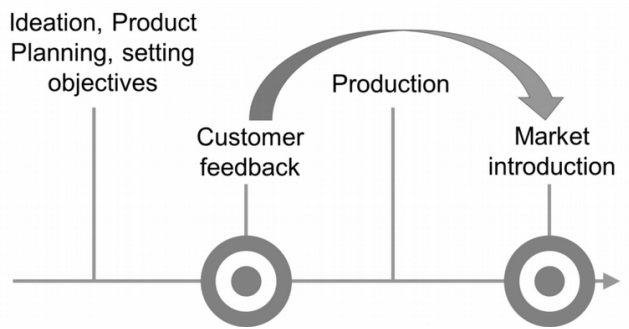

Figure 1. According to the classical timeline of product development initiatives, customer feedback could be no longer effective at the time of market launch, with clear repercussions in terms of success 


\section{Kano's Theory: Fundamentals and Main Limitations}

The present Section clarifies the aspects of Kano's theory of attractive quality that result critical for the scopes of the present research. The first subsection describes the fundamentals of the use of Kano-based techniques, while the second one discusses dynamic hypotheses regarding quality attributes. As critical issues deal with the abundant qualitative value of the findings, the third subsection introduces common measures to build quantitative parameters. The present paper remarks the benefits of using quantitative indexes in the perspective of performing forecasting and decision-making tasks, as better documented in Section 4.

\subsection{Overview of the Standard Kano Methodology}

Although alternative approaches have been developed to exploit Kano's fundamentals in both qualitative and quantitative ways, see (Violante \& Vezzetti, 2017), a standard procedure is usually followed, which refers to Walden (1993). A certain number of customers is asked about their feelings when a given product attribute is fulfilled (functional question) or absent (dysfunctional question), as shown in the illustrative example reported in Figure 2.

The combination of answers provided by each potential customer gives rise to the designation of a Kano category (or quality attribute) for each investigated property, as suggested by Figure 3. The category addressed by the majority of respondents is chosen as a reference quality attribute for the considered property. Although this designation strategy is challenged in the literature, Mikulić and Prebežac (2011) conclude that the traditional approach currently outperforms alternative proposals.

More in details, the discussed quality attributes are:

- one-dimensional features, which generate excitement if the performance is high and cause dissatisfaction if unfulfilled;

- must-be features, which can just contribute to avoid dissatisfaction;

- attractive features, which are just capable of arousing excitement if fulfilled, by basically fulfilling unspoken customer needs;

- indifferent features, playing a scarce role in determining customer satisfaction.

As reverse and questionable designations are considered the result of inaccurate definitions or wrong interpretations of questions, the present study focuses on the four above-listed quality attributes.

The quality attributes describe, in a qualitative way, different curves depicting the relationships between performance and perceived satisfaction, as classically represented like in Figure 4.

\begin{tabular}{|c|ll|}
\hline Functional question & $\square$ & I really like it \\
Shoes can be worn regardless the & $\square$ & It must be this way \\
external conditions, markedly & $\square$ & I don't care/l'm neutral \\
the environment and the & $\square$ & I can tolerate this/I can live with \\
weather & $\square$ & I dislike it \\
\hline Dysfunctional question & $\square$ & I really like it \\
Shoes cannot be worn regardless & $\square$ & It must be this way \\
the external conditions, & $\square$ & I don't care/l'm neutral \\
markedly the environment and & $\square$ & I can tolerate this/I can live with \\
the weather & $\square$ & I dislike it \\
\hline
\end{tabular}

Figure 2. Illustrative functional and dysfunctional questions of Kano surveys 


\begin{tabular}{|c|c|c|c|c|c|c|}
\hline \multirow{2}{*}{\multicolumn{2}{|c|}{$\begin{array}{l}\text { Customer Survey } \\
\text { Responses }\end{array}$}} & \multicolumn{5}{|c|}{ Dysfunctional Question Answer } \\
\hline & & \multirow{2}{*}{$\begin{array}{c}\text { 1. Like } \\
\text { Questionable }\end{array}$} & \multirow{2}{*}{$\begin{array}{l}\text { 2. Must Be } \\
\text { Attractive }\end{array}$} & \multirow{2}{*}{$\begin{array}{l}\text { 3. Neutral } \\
\text { Attractive }\end{array}$} & \multirow{2}{*}{$\begin{array}{l}\text { 4. Live with } \\
\text { Attractive }\end{array}$} & \multirow{2}{*}{$\begin{array}{c}\text { 5. Dislike } \\
\text { One-Dimensional }\end{array}$} \\
\hline \multirow{5}{*}{ 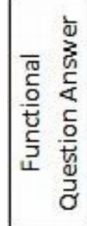 } & 1. Like & & & & & \\
\hline & 2. Must Be & Reverse & Indifferent & Indifferent & Indifferent & Must-Be \\
\hline & 3. Neutral & Reverse & Indifferent & Indifferent & Indifferent & Must-Be \\
\hline & 4. Live with & Reverse & Indifferent & Indifferent & Indifferent & Must-Be \\
\hline & 5. Dislike & Reverse & Reverse & Reverse & Reverse & Questionable \\
\hline
\end{tabular}

Figure 3. Procedure to designate quality attributes according to the responses to functional and dysfunctional questions

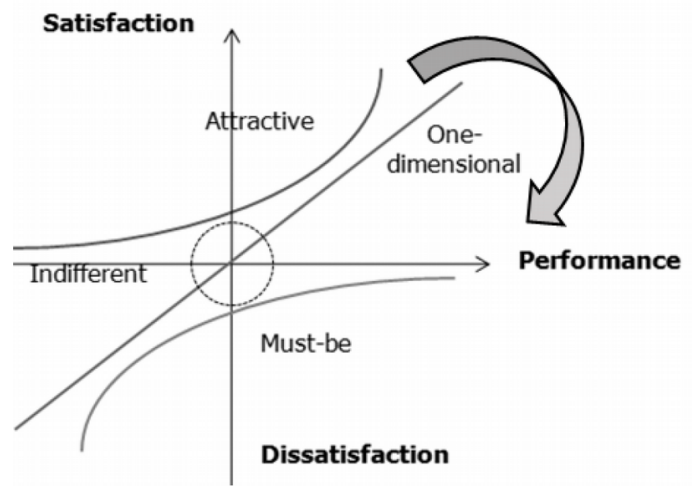

Figure 4. Quality attributes of Kano model and qualitative performance/satisfaction curves; the arrow represents the expected evolution of the categories

\subsection{Overview of the Standard Kano Methodology}

As already mentioned in Section 1, Kano (2001) hypothesizes the evolutionary nature of quality attributes. The nuances of different frameworks that accept the evolutionary behavior is discussed in (Borgianni \& Rotini, 2015). Beyond time, Nilsson-Witell and Fundin (2005) claim the role played by accumulated experience (as the time of adoption progresses) in the modification of Kano categories, confirmed by the insightful research reported in (Falk, Hammerschmidt \& Schepers, 2010).

Consistently with this standpoint, the dynamic pattern foresees changes in customers' perception as users get used to benefitting from certain functions and properties (see the curved arrow in Figure 4). As appreciation for a customer requirement is initially displayed in the fashion of an attractive quality attribute, this tends to switch towards one-dimensional and subsequently to must-be. In a certain sense, customer requirements tend to decrease their capability to generate satisfaction and their fulfilment is gradually more and more devoted to avoiding harm. According to certain keys of reading, customer requirements are classified as indifferent before turning into attractive features and/or after they can be characterized as must-be.

The Introduction section has clarified how this mechanism, albeit reasonable, lacks empirical support. Despite this fact, the discussed dynamic effects regard the core of decision-making schemas proposed and/or adopted by some scholars, e.g. (Raharjo, Brombacher, Goh \& Bergman, 2010).

\subsection{Quantitative Measures Descending from Kano's Model}

Kano's model is quintessentially qualitative, but quantitative formulations have been developed in order to make the methodology more supportive of decision-making. The most diffused quantification model of satisfaction and dissatisfaction still refers to Walden (1993). According to his indications, several scholars interpret the importance of product/service attributes as the rate of potentially satisfied and unsatisfied respondents to customer surveys. More specifically, the amount of must-be, one-dimensional and attractive designations for a given product attribute is considered as a proxy of its capability to generate satisfaction or avoid customer discontent due to the absence of expected characteristics or performances. These two complementary aspects are referred as two different indexes, i.e. Better (or "extent of satisfaction", CS) and Worse (or "extent of dissatisfaction", DS) coefficients, which are calculated through the formulas that follow. 


$$
\begin{aligned}
& \text { Better }=(A+O) /(A+O+M+I) \\
& \text { Worse }=(O+M) /(A+O+M+I)
\end{aligned}
$$

In the above equations, the terms $A, O, M$, and $I$ represent the number of designations provided by each respondent of the sample concerning Attractive, One-Dimensional, Must-be and Indifferent quality attributes, respectively. According to the presented dynamic Kano's model, the Better term supposedly prevails at first and then, as time progresses and experience is accumulated, the Worse index becomes more relevant.

\section{Methodological Approach and Description of the Study}

As introduced in Section 1, the scope of the paper is to investigate the possibility of using data from Kano surveys in order to anticipate the future impact of customer requirements on satisfaction. Discussed cyclical frameworks represent the initial hypothesis of this study, whose task is therefore the determination of the actual effect of time on the alteration of customer preferences.

From a formal point of view, such an assessment should be performed through repeated-measures experiments. In the considered case, it would consist in re-administering Kano questionnaires about the features of a given product or service to identical samples of consumers. This would reveal whether accumulated experience, elapsed time and routine to certain benefits have indisputably played a twisting effect on the perception of satisfaction and dissatisfaction. According to author's experience and results from the exploration of the literature, such a task has not been performed so far.

It is worth noticing that possible barriers can arise to conduct repeated-measures tasks concerning Kano's model, such as unavailability of subjects involved at a first stage and non-predictable effects brought on by gained confidence with this sort of questionnaire.

\subsection{Approach to Conduct the Study}

As the obstacles to carry out repeated-measures experiments are clear and a not negligible amount of time and resources would be required to extract sound results (Borgianni, 2016), the author considered the opportunity of leveraging the abundant, although dispersed, literature about case studies conducted through Kano's model. The objective is extracting cases in which the same customer requirements for the same products and services have been surveyed in different research studies and, subsequently, to assess the effect of time on modifications of the quality attributes through statistical instruments. The methodological approach follows.

By using Google Scholar, i.e. one of the richest collections of academicians' and practitioners' publications, the author individuated dozens of documents in which applications of Kano's model are reported. All the sources were classified according to the field of application, in order to identify products and services for which multiple Kano investigations have been performed. Within the sets of case studies characterized by the same domain, the lists of investigated customer requirements or product functionalities have been extracted. All the case studies have been compared in order to individuate multiple investigations of the same attributes evaluated through the lenses of Kano model. This has made it possible to reveal the existence of different surveys concerning certain benefits that have been taken place in different years. Indeed, for the purpose of the present study, the author has not considered the cases in which the same customer requirements have been investigated more times in the same year. Some clarifications follow.

- The extraction of information has been limited to the results of Kano surveys; more clearly, although some sources were evaluated as poorly trustworthy from a scientific point of view, e.g. because of inaccurate review policies, the outcomes of Kano applications were considered reliable.

- The years in which surveys have been conducted are not declared in each publication; in the cases in which such information is not available, the years of papers' first submission have been taken into account. 
- As the focus of the investigation was the dynamics of Kano-related constructs (firstly quality attributes, secondly Better and Worse terms, as better explained in the residual of the paper), the author directly extracted relevant data when available or declared; more precisely:

- when the definition of the quality attributes has been performed through the classical procedure, i.e. by individuating the most diffused cluster in the sample, data have been directly exploited; in the cases in which different criteria have been employed, the author performed the definition of the quality attributes on the basis of available data; as for publications reporting Kano surveys administered to different groups of respondents, data have been aggregated in order to individuate the most representative quality attribute for each customer requirement;

- when Better and Worse values were not given, but it was possible to determine them through the formulas (1) and (2), the author calculated said terms.

- In the cases in which the same authors report results of Kano investigations in multiple papers, the oldest one has been considered as a reference.

- When customer requirements have undergone Kano investigations more than twice, the author has considered the surveys in a sequential way; for example, in case of three investigations available, data of the first one against the second one and of the second one against the third one have been compared.

\subsection{Description of the Dataset Gathered By the Literature Investigation}

The process described in the previous subsection has led to the identification of 176 couples of data, constituted by different results of Kano analyses for specific customer requirements in the same industry. For each couple, the examination has considered the status of the designated quality attribute in a first and second Kano survey. Table 1 summarizes the reference industries of the couples, the number of investigated product/service attributes and the exploited scientific sources.

A more detailed version of the table is publicly available at the link https://drive.google.com/open? $\underline{\mathrm{id}=1}$ 5n26VhQfMip pU4Q2fkwd6EnKMDWalt, which includes:

- the industrial fields in which akin customer requirements have been identified;

- the definition of each customer requirement, whose name can differ in the two surveys, but it is clearly referred to the same function or benefit;

- the literature sources in which the surveys are described;

- the years in which initial and subsequent Kano surveys have been expectedly performed, which enables the determination of the time elapsed between the two studies;

- where available, data concerning Better and Worse indexes - they have been found or extrapolated for a subset of 145 changing product or service requirements. 


\begin{tabular}{|c|c|c|}
\hline $\begin{array}{l}\text { Reference product } \\
\text { or service }\end{array}$ & $\begin{array}{l}\text { Number } \\
\text { of couples }\end{array}$ & Sources \\
\hline Apparel and textiles & 4 & Redfern and Davey (2003); Bennur and Jin (2013) \\
\hline Banking & 33 & $\begin{array}{l}\text { Bhattacharyya and Rahman (2004); Strandberg, Wahlberg and Öhman (2012); Zarei, } \\
\text { Hemati and Rafeeian (2012); Seyedi, Shirazifar, Dalvand and Zohdi (2012); Modaresi } \\
\text { and Mehrara (2014) }\end{array}$ \\
\hline E-learning & 11 & $\begin{array}{l}\text { Chen and Lin (2007); Kastner and Stangl (2011); Bauk, Šćepanović and Kopp (2014); } \\
\text { Violante and Vezzetti (2015) }\end{array}$ \\
\hline Healthcare & 7 & $\begin{array}{l}\text { Dwi and Nora (2012); Chang and Chang (2013); Momani, Al-Hawari, Al-Shebami } \\
\text { and Al-Araidah (2014) }\end{array}$ \\
\hline Hospitality & 34 & $\begin{array}{l}\text { Erto and Vanacore (2002); Jen and Bueso (2010); Chang and Chen (2011); Gupta and } \\
\text { Srivastava (2011); Lin, Tsai, Wang, Su and Shaw (2011); Yang, Jou and Cheng (2011); } \\
\text { Dominici and Palumbo (2013); Ho, Peng, Feng and Yen (2013) }\end{array}$ \\
\hline $\begin{array}{l}\text { Methods for NPD } \\
\text { and Product Lifecycle } \\
\text { Management }\end{array}$ & 3 & Lee, Lin and Wang (2011); Violante and Vezzetti (2014) \\
\hline Mobile telephones & 6 & Wu and Wang (2012); Tontini and Picolo (2013) \\
\hline Notebooks & 6 & Tang and Huang (2004); Wang and Ji (2010) \\
\hline Packaging & 23 & Löfgren and Witell (2005); Regattieri, Santarelli and Olsson (2012) \\
\hline Ski resorts & 2 & Füller and Matzler (2008); Żemła (2008) \\
\hline Trains and railways & 8 & Lai and Wu (2011); Lin, Hsieh and Huang (2012) \\
\hline University education & 35 & $\begin{array}{l}\text { Bilgili and Unal (2008); Khalid, Mustafa and Haque (2008); Kumar, Balasubramanian, } \\
\text { Suresh and Arularasu (2010); Lajevardi, Fakharmanesh, Emami and Lajevardi (2012); } \\
\text { Sukwadi, Yang and Liu (2011); Arefi, Heidari, Morkani and Zandi (2012); Dominici, } \\
\text { Palumbo and Basile (2012) }\end{array}$ \\
\hline Websites & 4 & Zhang and von Dran (2001); Zhifeng (2007); Chaudha, Jain, Singh and Mishra (2011) \\
\hline
\end{tabular}

Table 1. Dataset of different Kano surveys investigating akin customer requirements

\subsection{Employed Statistical Tools: Criteria and Choices}

The core of the investigation consisted in determining whether statistical models can be extracted from real data that reflect the variations of Kano categories, as foreseen through dynamic frameworks. Still consistently with these transition models, it is worth noting that, according to the initial quality attribute, the appearing of certain dominant categories are initially probable and, subsequently, more and more unlikely. For example, if we consider an attractive customer requirement, the probability of its transformation into a one-dimensional one is high after a given amount of time, but not particularly viable over time, as its designation as must-be is supposedly the most likely. In this sense, a time-linear statistical model was considered inappropriate to show the expected trajectories and the author has therefore included also the square of time within explanatory factors.

As well, the probability of facing a certain designation after a certain amount of time depends on the initial quality attributes.

As Kano categories represent nominal variables, a multinomial logistic regression was deemed as the most appropriate statistical model to be adopted. It can be noted that nominal variables are both inputs and outputs of the regression. Time-related factors, as anticipated, are additional predictors.

In parallel, the author exploited the transformations of Better and Worse indexes in order to extract regression functions with quantitative variables. Despite the smaller number of available observations and the infrequent use of these terms to support decisions, the advantages of using these indexes will become apparent in the next section.

The extraction of all statistical functions has been carried out by using the software Stata MP13. 


\section{Outcomes of the Study}

\subsection{Evolution of Kano's Quality Attributes}

The outputs of the chosen regression model are provided in terms of log odds, which are proxies of the likelihood of turning into a given response with respect to another option (base outcome, i.e. a specific quality attribute automatically chosen by the system, One-dimensional in this case) and which are influenced by the chosen explanatory factors (the time parameters and the quality attribute of the first Kano survey). The data are presented in Table 2, which includes the followings:

- $q a 1$ and $q a 2$ are the labels associated with the quality attributes at the first and second evaluation;

- years and_sqryears are the time parameters used as regressors, to which the initial designation of the quality attribute was added $(A, M$ and $O$ here stand for Attractive, Must-be and One-dimensional in the figure; Indifferent is not included, as introducing all the four possibilities would have been superfluous);

- the coefficients associated to the regressors are to be found in the third column; the third column reports the standard deviations for these coefficients; p-values are also included, standing for the significance of the parameters in the regression function (the lower the value, the more significant the parameter).

\begin{tabular}{|c|c|c|c|c|}
\hline qa2 & Coefficient & $\begin{array}{l}\text { Regression } \\
\text { coefficient }\end{array}$ & Std. Error & p-value \\
\hline \multirow{7}{*}{ Indifferent } & years & -0.169 & 0.455 & 0.710 \\
\hline & _sqryears & 0.008 & 0.049 & 0.870 \\
\hline & $q a 1$ & & & \\
\hline & $A$ & -0.743 & 0.728 & 0.308 \\
\hline & $O$ & -1.062 & 0.593 & 0.073 \\
\hline & $M$ & -1.196 & 0.697 & 0.086 \\
\hline & _cons & 0.887 & 0.969 & 0.360 \\
\hline \multirow{7}{*}{ Attractive } & years & -1.175 & 0.433 & $0.007^{* *}$ \\
\hline & _sqryears & 0.118 & 0.046 & $0.010^{* *}$ \\
\hline & $q a 1$ & & & \\
\hline & $A$ & -0.406 & 0.834 & 0.627 \\
\hline & $O$ & -0.419 & 0.690 & 0.544 \\
\hline & $M$ & -0.264 & 0.752 & 0.726 \\
\hline & _cons & 1.723 & 0.964 & 0.074 \\
\hline One-dimensional & \multicolumn{4}{|c|}{ (base outcome) } \\
\hline \multirow{7}{*}{ Must-be } & years & -1.172 & 0.410 & $0.000^{* * *}$ \\
\hline & _sqryears & 0.166 & 0.044 & $0.000^{* * *}$ \\
\hline & $q a 1$ & & & \\
\hline & $A$ & -0.532 & 1.016 & 0.600 \\
\hline & $O$ & 0.793 & 0.784 & 0.312 \\
\hline & $M$ & 1.040 & 0.822 & 0.206 \\
\hline & _cons & 2.346 & 0.985 & 0.017 \\
\hline
\end{tabular}

Table 2. Outcomes of the multinomial logistic regression that links log odds of designated quality attributes for a given customer requirement in two different Kano surveys, where time elapses from the previous to the subsequent one; *, ** and ${ }^{* * *}$ stand for significance levels corresponding to p-values minor than $0.05,0.01$ and 0.001 , respectively 
At first, as for the overall regression function, it is possible to add the following information:

- the $\chi^{2}$ test performed by the software ensures that the model as a whole fits significantly better than an empty model, i.e. a model with no predictors;

- the Pseudo $R^{2}$ is also calculated (0.099). It represents a measure of the explanatory power of the model; in other words, the initial quality attributes and the elapsed time are responsible for the description of the studied phenomenon to an extent that approximately equals to $10 \%$.

In order to use the coefficients for extracting the probabilities of designating a customer requirement after a given amount of time, the following equation has to be taken into account.

$$
\log \left(P_{j} / P_{\text {one-dimensionala }}\right)=\_ \text {const } t_{j}+\_q 1_{j}+\_ \text {years } j \cdot x+\_ \text {sqryears }_{j} \cdot \chi^{2}
$$

In (3), $P$ are the probabilities associated with a quality attribute $j$ (other than One-dimensional, which is the base output as mentioned above), $x$ is the time measured in years after the first Kano survey, the parameters preceded by the underscore are the coefficients extracted by the regression:

- _ _const $t_{j}$, years $j_{j}$, sqryears $_{j}$ refer to the quality attribute $j$ for which the probability is calculated;

- $\quad q a 1_{j}$, still refers to the quality attribute $j$ and it has to be selected according to the Kano category revealed at the first survey (qa1), if not Indifferent.

This makes it possible to calculate probabilities by benefitting from the transformation of the expression above and by considering that the sum of the probabilities concerning the four quality attributes has to be 1 at any given time. It thus results that:

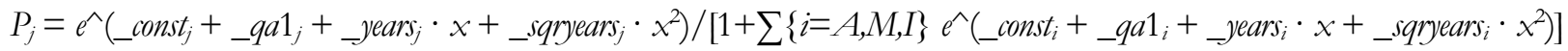

In (4), the numerator is 1 when the probability is computed for the quality attribute becoming One-dimensional.

The author has elaborated the data further in order to provide readers with clearer figures and built diagrams that express the expected trajectories of Kano categories' probability. The curves of Figures 5-8 describe the variation of the probability of observing the designation of each quality attribute after a given number of years according to the initial Kano category. The starting one is indicated in both each diagram and the caption of each Figure. The curves with the same line fashion are associated with the probability referred to the same quality attributes across the various illustrations. As well, such an association is recalled within each picture.

\subsubsection{Trajectories of Attractive Customer Requirements}

The initial hypothesis about attractive attributes is turning into one-dimensional and then into must-be requirements. Figure 5 confirms this trend to a large extent, as the probability of one-dimensional designations grows distinctly at the beginning of the curve and then decreases, as must-be attributions become more and more likely. The (almost) steady decline of indifferent attributions complies with the discussed dynamic models. Conversely, the growing probability of new attractive designations results the most unexpected feature of the diagram. 


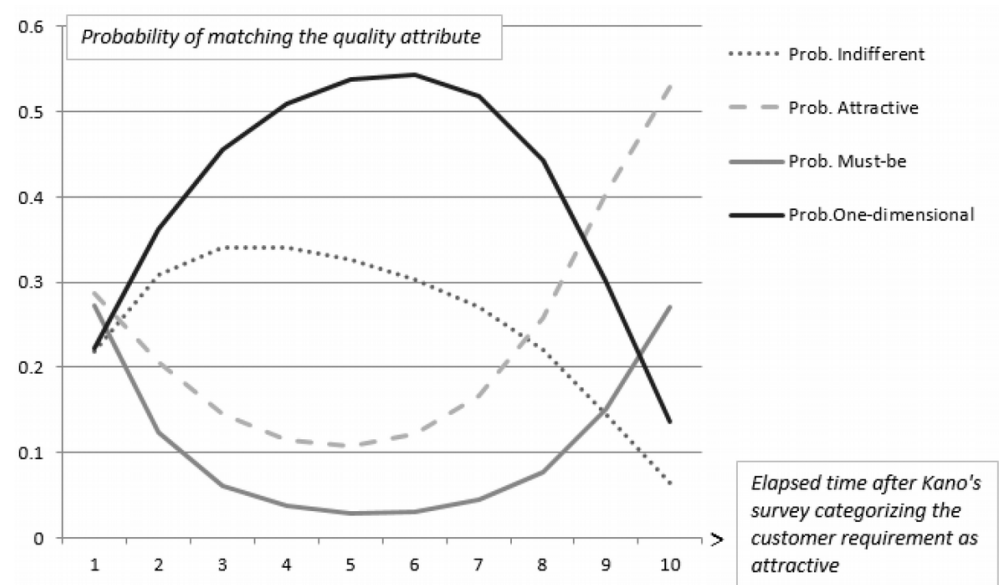

Figure 5. Expected trajectories of customer requirements designated as attractive

\subsubsection{Trajectories of One-dimensional Customer Requirements}

According to dynamic Kano models, it is expected that one-dimensional characteristics will become must-be as time progresses and customers' experience is accumulated. With respect to Figure 6, this phenomenon seems to be confirmed and, on the average, this should be observed 5-7 years after the initial Kano survey. Indeed, the ending parts of the curves remark the drop of likelihood of one-dimensional designations and an abrupt increase of mustbe attributions' probability. The chance of observing transformations into attractive and (especially) indifferent quality attributes is quite low and this circumstance matches with dynamic Kano frameworks too.

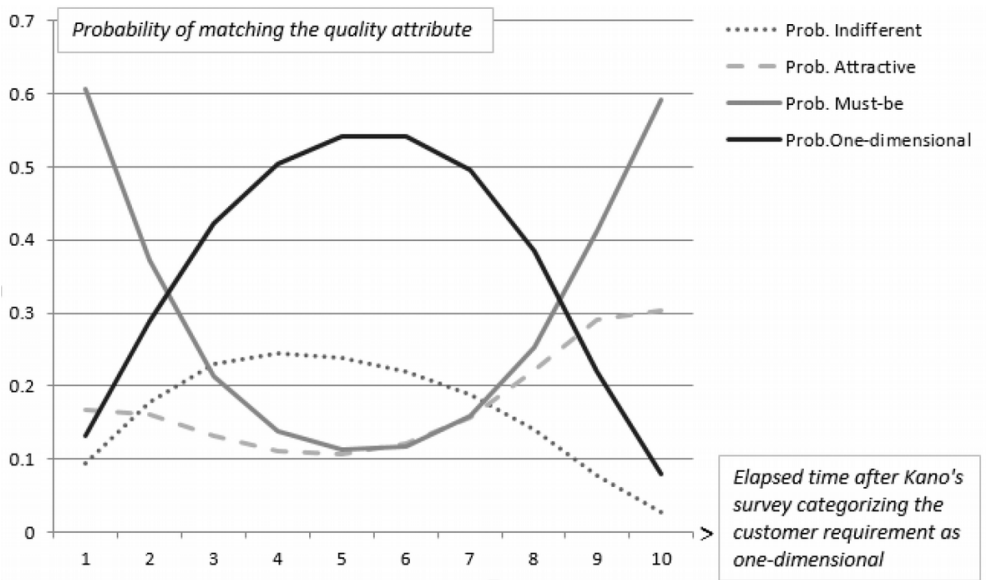

Figure 6. Expected trajectories of customer requirements designated as one-dimensional

\subsubsection{Trajectories of Must-Be Customer Requirements}

Evolutionary Kano models postulate the consolidation of must-be attributions over time. Transformations into indifferent requirements can be somehow expected with respect to certain functions that are not valued anymore by customers. However, we could argue that this does not hold if the customer requirement is expressed in terms of the benefit associated with the function, rather than with the function itself. Figure 7 does not confirm the initial hypothesis, at least qualitatively. While new must-be designations are overall the most probable in the future, transformations into one-dimensional requirements are not unlikely to take place. On the other hand, switches to attractive and indifferent quality attributes are not probable. 


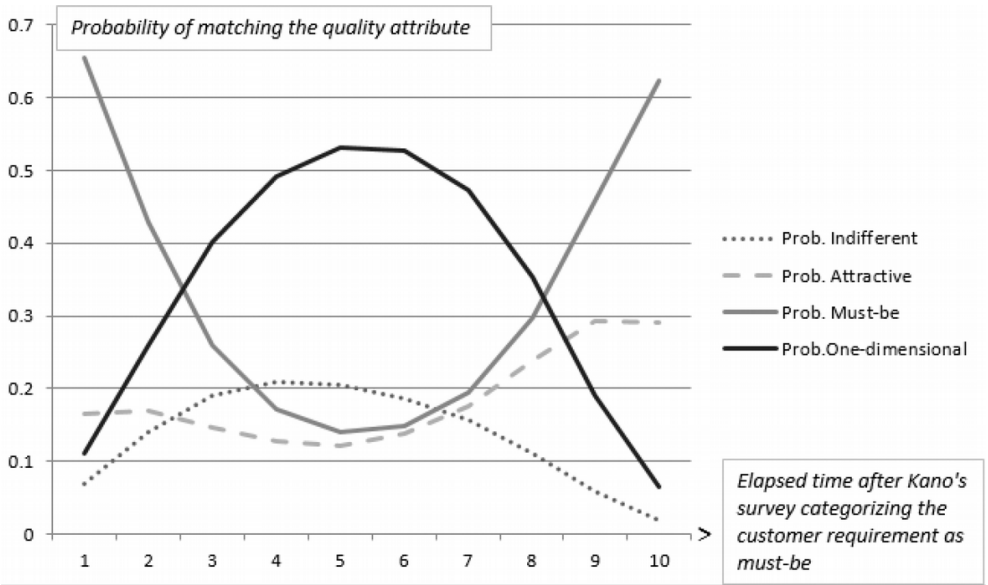

Figure 7. Expected trajectories of customer requirements designated as must-be

\subsubsection{Trajectories of Indifferent Requirements}

As Figure 8 suggests, the transformation of indifferent requirements is quite unpredictable according to the statistical model. Dynamic models do not give particular emphasis on indifferent attributes, although it is supposed that either they will play a minor role throughout the whole historical product evolution or they will turn into attractive elements at a certain point in time and follow the trajectory of exciters subsequently. The diagram confirms such a hypothesis just partially.

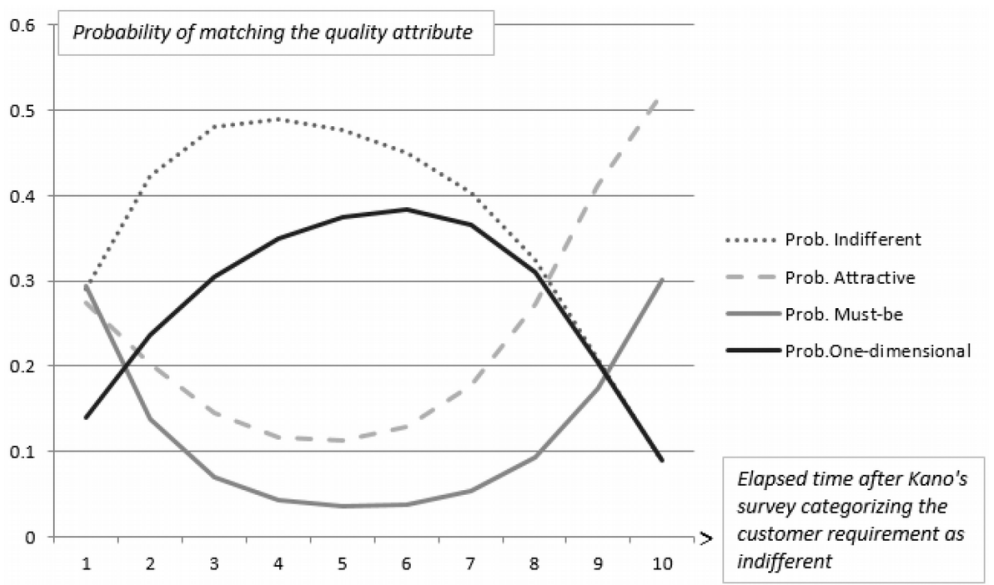

Figure 8. Expected trajectories of customer requirements designated as indifferent

\subsubsection{Further Notes About Extracted Functions}

Some comments follow with regard to the reliability and usability of the presented results.

First, with respect to the regression model, it is worth noting that acknowledged logistic models with nominal variables as a response variable cannot be constrained to certain values (at least in author's knowledge). In the treated case, it would result useful to bind the outcomes of quality attributes' probabilities in terms of assigning $100 \%$ chance to the initial Kano category after 0 years. This cannot be extrapolated in any of the illustrated diagrams. This aspect clearly affects the accuracy of the curves. However, the utility of the graphs is limited for medium-term considerations, since product development teams can rely on extracted customer data after little time is elapsed. According to statistical rules, the most reliable indications refer to regions characterized by those regressors' values that are the most frequent in the dataset. For the sake of completeness, the average time difference between the 176 couples is about 4 years (the standard deviation equals roughly to 2.5 years). In other terms, the reliability of the forecasts diminishes as the difference between the abscissas' value and 4 increases. 
However, information from the literature (Bourgeon, 2007) suggests that the most reliable region of the curves corresponds to the time elapsed from product design to market launch for medium- and long-term NPD strategies. As many curves seem to deviate from the expected trajectory especially in the final part of the diagram, this can be partially due to the necessity of using square of time in the regression function.

Second, the coefficients associated to explanatory factors in the four regression functions are not all statistically relevant ( $\mathrm{p}$-value $<0.05$ is considered to the scope as a rule of thumb). This fact is not surprising, if we consider the limited extension of the dataset with respect to the outreach of this preliminary research, i.e. observing quality attributes' fluctuations for any kind of customer requirement and industry in a worldwide perspective. Nevertheless, some coefficients are statistically significant and compliant with expectations, e.g. the decreasing probability of the transformation of a quality attribute into Attractive if time at the first-grade is considered. In this context, a further factor complicating the matters could be represented by the rapidity of changes that are commonly associated with technology-intensive sectors if compared with traditional industries.

Third, through the already discussed value of goodness-of-fit associated with the regression function (Pseudo $R^{2}$ ), it is possible to assess the role played by time, or at least by the two time-related explanatory factors used in the statistical analysis. Other factors, which have been deliberately overlooked in the present paper, have expectedly major explanatory power. Anyway, the included regressors are undoubtedly worth investigating, as already recalled in Section 4.1.

\subsection{Evolution of Quantitative Indexes}

\subsubsection{Construction of the Statistical Functions}

As clarified in Section 3.3, the author performed a statistical analysis of transformations occurred to Better and Worse indexes. With reference to this task, it is worth noting that:

- the number of observations is lower, but the outputs are smaller in number and not mutually dependent (differently than the probabilities of quality attributes);

- the general acceptance and employment of the discussed indexes is lower with respect to the quality attributes, but the different variables can be linked to each other, as suggested by Xu, Jiao, Yang, Helander, Khalid and Opperud (2009); Figure 9 illustrates a reference schema that shows the most probable quality attribute by knowing Better and Worse values; Table 3 informs about the average values of Better and Worse that have been met during this study for each of the considered Kano categories;

- the employment of quantitative variables allows for an easier application of the regression results.

Two distinct functions have been extracted for the variations of Better and Worse indexes. The time elapsed has been considered in the form of years and square years, like in the regression focusing on the quality attributes. The initial magnitudes of Better and Worse indexes have been considered as regressors as well, with the aim to adapt the functions to the initial state of customer satisfaction towards the examined product requirements. Outcomes are presented in Table 4, which includes, besides regression coefficients (whose meaning will become more apparent in the following), their standard deviations and p-values consistently with the previous statistical experiment. In both cases, the $\chi^{2}$ test ensures that the models fit significantly better than an empty model. $R^{2}$ values are roughly $42 \%$ and $25 \%$ for the functions concerning the variation of Better and Worse indexes, respectively.

\begin{tabular}{|l|r|r|}
\hline \multicolumn{1}{|c|}{ Quality attribute } & Mean Better value & Mean Worse value \\
\hline Attractive & 0.66 & 0.37 \\
\hline One-dimensional & 0.63 & 0.69 \\
\hline Must-be & 0.39 & 0.71 \\
\hline Indifferent & 0.33 & 0.26 \\
\hline
\end{tabular}

Table 3. Average values of Better/Worse indexes for the four reference quality attributes 


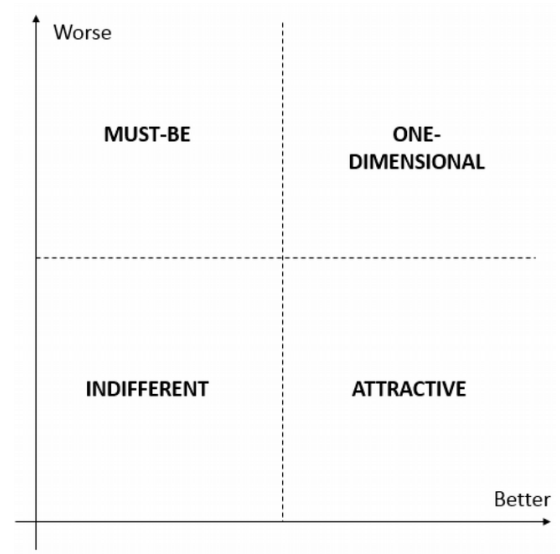

Figure 9. Characteristic areas of quality attributes according to the low or high values of the Better/Worse indexes

\begin{tabular}{|c|c|c|c|c|}
\hline Variation & Coefficient & $\begin{array}{l}\text { Regression } \\
\text { Coefficient }\end{array}$ & Std. Error & p-value \\
\hline \multirow{4}{*}{$\Delta$ better } & better1 & -0.722 & 0.075 & $0.000^{* * *}$ \\
\hline & worse1 & 0.138 & 0.067 & $0.042^{*}$ \\
\hline & years & 0.160 & 0.024 & $0.000^{* * *}$ \\
\hline & _sqryears & -0.016 & 0.003 & $0.000^{* * *}$ \\
\hline \multirow{4}{*}{$\Delta$ worse } & better1 & 0.222 & 0.084 & $0.010^{* *}$ \\
\hline & worse1 & -0.484 & 0.076 & $0.000^{* * *}$ \\
\hline & years & 0.062 & 0.027 & $0.024^{*}$ \\
\hline & _sqryears & -0.006 & 0.003 & 0.057 \\
\hline
\end{tabular}

Table 4. Outcomes of the linear regressions that predict the alteration of Better and Worse indexes; the meaning of superscripts is consistent with Table 2

Based on Table 4, the extrapolated equations follow.

$$
\begin{gathered}
\Delta \text { Better }=-0.722 \cdot \text { Better } 1+0.138 \cdot \text { Worse } 1+0.160 \cdot \text { _years }-0.016 \cdot \text { _sqryears } \\
\Delta \text { Worse }=0.222 \cdot \text { Better } 1+0.484 \cdot \text { Worse } 1+0.062 \cdot \text { _years }-0.006 \cdot \text { _sqryears }
\end{gathered}
$$

The parameters of the formulas are explained in the followings:

- $\quad \Delta B e t t e r$ and $\Delta W$ orse represent the variation of the two indexes;

- $\quad$ Better 1 and Worse 1 represent the initial values of the indexes;

- _years and_sqryears represent the elapsed time in years for which the prediction is performed and its square, respectively.

Thanks to the obtained functions (5) and (6), it is possible to determine the expected future state of customer satisfaction towards a given requirement, as in Figure 10, which considers the initial mean values of Better and $W$ orse for an attractive customer requirement. 


\subsubsection{Comments on the Extracted Functions}

Although the magnitude of uncertainty is not negligible also in this statistical task, the reliability of regression parameters is much higher. All the regression coefficients are featured by p-values lower than 0.05 , except for the _sqryears in the equation (6). The explanatory capability of the functions is more significant than in the case of probabilities' estimation of quality attributes, as achievable by comparing $R^{2}$ data.

Despite the choice of omitting constants in the functions, the 0-years effect has not been overcome, as clearly visible in Figure 10. In each case, the highest reliability of the functions refer to the mid-term (roughly 4 years) also through the use of the presented functions concerning Better and Worse indexes. Both the trajectories of Better and Worse functions consist in concave downward curves. This suggests that both indexes tend do decrease in the long term. This observation is consistent with the initial hypotheses concerning the Better term, but not with respect to the Worse index, as this circumstance would imply minor dissatisfaction in case of the absence of a given benefit in the long term. In each case, the Worse index tends to prevail in the long term, complying with the proposed dynamics of Kano's quality attributes.

Trajectories of Better/Worse indexes for Attractive attributes

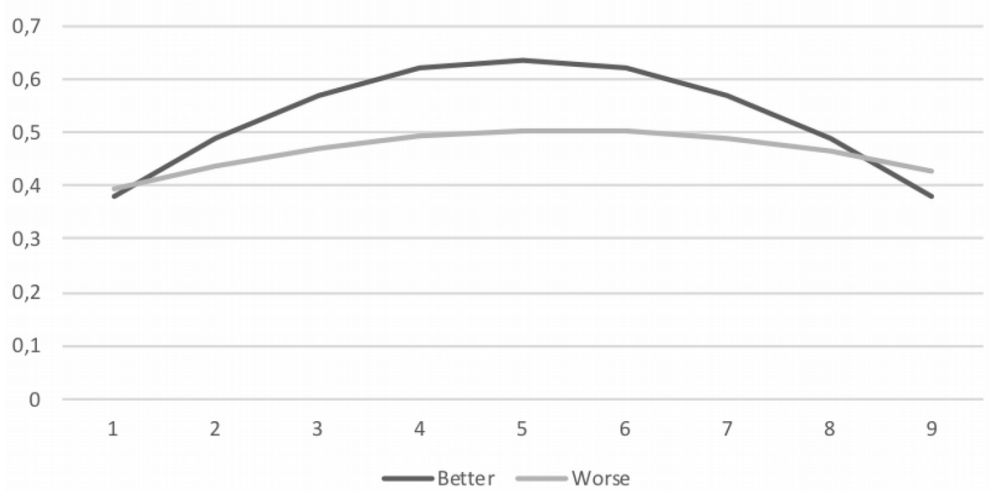

Figure 10. Expected trajectories of Better and Worse indexes for an attractive requirement

\section{Final Remarks and Future Work}

Taking the cue from the dynamic models that underpin the evolutionary nature of Kano's quality attributes, the author examined variations of Kano-related constructs in order to forecast the future relevance of customer requirements. The possibility of predicting the role of product attributes is particularly relevant for design tasks swiveling on VoC-based approaches.

Despite methodological limitations that are recalled in the previous sections, the statistical analysis of a large number of Kano surveys provides a partial verification of hypothesized trends followed by customer requirements. Said trajectories foresee the increasing role of relevant characteristics in terms of avoiding customer dissatisfaction rather than working as exciters. The confirmation of these trends arises from two distinct studies, which use dissimilar constructs belonging to Kano's theory and differ in terms of usability and reliability. The former predicts the probability of matching a specific quality attribute after a certain number of years, thus suggesting the extent to which a given product/service feature will be capable of generating satisfaction or provoking dissatisfaction (if unfilled). The latter makes use of quantitative measures of the mentioned nuances of customer satisfaction and projects their future values. If sufficient information is available, the latter can be recommended, given the major reliability of the extracted statistical functions.

Because of not marginal degrees of uncertainty, it could result extremely hazardous to rely on the presented curves for forecasting purposes. The author wills to clarify that, at the present stage of the research, the suggestions arising from the extracted statistical models can support decision-making in design and quality management just from a qualitative point of view. In addition, the overwhelming majority of analyzed case studies from the service industry 
can affect the applicability of the results within design and manufacturing of physical goods. However, despite the recalled extent of uncertainty, the results clearly address the relevance of changes of customer preferences, which should not be overlooked in NPD initiatives.

With the aim to enhance the reliability of the presented models, future work is planned. On the one hand, the working dataset will be expanded as new surveys employing Kano's model will be divulgated, so as to exploit resources from the literature to the greatest extent. The construction of increasingly reliable statistical models will be accompanied by a specific consideration of uncertainty. On the other hand, future studies will try to take into account other factors that have been neglected up to the present state, including demographic factors and the supposed different speed of change connected with diverse industrial domains.

Eventually, Kano surveys on specific products and customer requirements will be conducted independently to observe the consistency of the outcomes with the findings of the paper.

The author is available to share details about some data that have been omitted in the paper for the sake of brevity.

\section{Declaration of Conflicting Interests}

The author declared no potential conflicts of interest with respect to the research, authorship, and/or publication of this article.

\section{Funding}

The research is fully supported by the project "ChANging design requirements - aCquiring knowledge from ApplicatioNs of attractive quality theory" (CAN-CAN), funded by the Free University of Bozen|Bolzano.

\section{References}

Arefi, M., Heidari, M., Morkani, G.S., \& Zandi, K. (2012). Application of Kano Model in higher education quality improvement: Study master's degree program of educational psychology in State Universities of Tehran. World Applied Sciences Journal, 17(3), 347-353.

Bacciotti, D., Borgianni, Y., Cascini, G., \& Rotini, F. (2016). Product Planning techniques: investigating the differences between research trajectories and industry expectations. Research in Engineering Design, 27(4), 367-389. https://doi.org/10.1007/s00163-016-0223-6

Bauk, S., Šćepanović, S., \& Kopp, M. (2014). Estimating Students' Satisfaction with Web Based Learning System in Blended Learning Environment. Education Research International, Article ID 731720. https://doi.org/10.1155/2014/731720

Bennur, S., \& Jin, B. (2013). Cross-cultural investigation of US and Indian consumer's apparel attribute choices applying Kano's theory. Journal of Fashion Marketing and Management: An International Journal, 17(3), 306-321. https://doi.org/10.1108/JFMM-03-2012-0007

Bhattacharyya, S.K., \& Rahman, Z. (2004). Capturing the customer's voice, the centerpiece of strategy making: A case study in banking. European Business Review, 16(2), 128-138. https://doi.org/10.1108/09555340410524238

Bilgili, B., \& Unal, S. (2008). Kano Model Application for Classifying the Requirements of University Students. In 7th Annual MIBES International Conference. Greece.

Borgianni, Y. (2016). Kano's method in product design: a study of dynamic models'reliability. In DS 84: Proceedings of the DESIGN 2016 14th International Design Conference.

Borgianni, Y., \& Rotini, F. (2015). Towards the fine-tuning of a predictive Kano model for supporting product and service design. Total Quality Management \& Business Excellence, 26(3-4), 263-283.

https://doi.org/10.1080/14783363.2013.791119

Bourgeon, L. (2007). Staffing approach and conditions for collective learning in project teams: The case of new product development projects. International Journal of Project Management, 25(4), 413-422.

https://doi.org/10.1016/j.ijproman.2007.01.014 
Chang, K.C., \& Chen, M.C. (2011). Applying the Kano model and QFD to explore customers' brand contacts in the hotel business: A study of a hot spring hotel. Total Quality Management, 22(1), 1-27.

https://doi.org/10.1080/14783363.2010.529358

Chang, W.J., \& Chang, Y.H. (2013). Patient satisfaction analysis: Identifying key drivers and enhancing service quality of dental care. Journal of Dental Sciences, 8(3), 239-247. https://doi.org/10.1016/j.jds.2012.10.006

Chaudha, A., Jain, R., Singh, A.R., \& Mishra, P.K. (2011). Integration of Kano's Model into quality function deployment (QFD). The International Journal of Advanced Manufacturing Technology, 53(5-8), 689-698.

https://doi.org/10.1007/s00170-010-2867-0

Chen, L.H., \& Lin, H.C. (2007). Integrating Kano's model into E-learning satisfaction. In Industrial Engineering and Engineering Management, 2007 IEEE International Conference on (297-301). IEEE.

https://doi.org/10.1109/IEEM.2007.4419199

Chong, Y.T., \& Chen, C.H. (2010). Customer needs as moving targets of product development: a review. The International Journal of Advanced Manufacturing Technology, 48(1-4), 395-406. https://doi.org/10.1007/s00170-009-2282-6

Dominici, G., \& Palumbo, F. (2013). The drivers of customer satisfaction in the hospitality industry: applying the Kano model to Sicilian hotels. International Journal of Leisure and Tourism Marketing, 3(3), 215-236.

https://doi.org/10.1504/IJLTM.2013.052623

Dominici, G., Palumbo, F., \& Basile, G. (2012). La Customer Satisfaction dei Servizi Bibliotecari Universitari. Uno Studio Empirico su Due Biblioteche Universitarie Italiane con il Modello di Kano (Customer Satisfaction of University Library services. An empirical study on two Italian University Libraries with Kano model). Proceedings of the IX Annual Convention of the Italian Marketing Society "International Marketing and Country-of-Origin Effect". Benevento, Italy. In Italian.

Dwi, S., \& Nora, M. (2012). Integrating Kano’s Model and SERVQUAL to Improve Healthcare Service Quality. Global Public Health, 132-146.

Erto, P., \& Vanacore, A. (2002). A probabilistic approach to measure hotel service quality. Total Quality Management, 13(2), 165-174. https://doi.org/10.1080/09544120120102405

Falk, T., Hammerschmidt, M., \& Schepers, J.J. (2010). The service quality-satisfaction link revisited: exploring asymmetries and dynamics. Journal of the Academy of Marketing Science, 38(3), 288-302.

https://doi.org/10.1007/s11747-009-0152-2

Füller, J., \& Matzler, K. (2008). Customer delight and market segmentation: An application of the three-factor theory of customer satisfaction on life style groups. Tourism Management, 29(1), 116-126.

https://doi.org/10.1016/j.tourman.2007.03.021

Gupta, P., \& Srivastava, R.K. (2011). Analysis of customer satisfaction of the hotel industry in India using Kano Model \& QFD. International Journal of Research in Commerce, IT \& Management, 2(1), 74-81.

Ho, L.H., Peng, T.F., Feng, S.Y., \& Yen, T.M. (2013). Integration of Kano’s model and SERVQUAL for enhancing standard hotel customer satisfaction. African Journal of Business Management, 7(23), 2257-2265.

Jen, H., \& Bueso, M.A.S. (2010). Investigating the Service Quality Attributes of International Backpackers using the Kano Model. The 11th Asia Pacific Industrial Engineering and Management Systems Conference.

Kano, N. (2001). Life cycle and creation of attractive quality. In 4th QMOD Conference (18-36). Linköping, Sweden,.

Kano, N., Seraku, N., Takahashi, F., \& Tsuji, S. (1984). Attractive quality and must-be quality. The Journal of the Japanese Society for Quality Control, 14(2), 39-48.

Kastner, M., \& Stangl, B. (2011). (Dis-) Satisfiers for e-Learning User Interfaces. Thirty Second International Conference on Information Systems. Shanghai, PRC.

Khalid, M.S., Mustafa, A., \& Haque, I. (2008). Application of Kano's Model for Evaluating Information Quality of University Websites. In SWWS (277-280). 
Kim, J., Geum, Y., \& Park, Y. (2017). Integrating customers' disparate technology readiness into technological requirement analysis: an extended Kano approach. Total Quality Management \& Business Excellence, 28(5-6), 678-694. https://doi.org/10.1080/14783363.2015.1105102

Kumar, M.P.S., Balasubramanian, S., Suresh, R.K., \& Arularasu, S. (2010). Application of Kano Model for classifying the requirements of engineering students. International Journal of Mechanical Engineering and Technology, 1(1), 1-6.

Lai, H.-J., \& Wu, H.-H. (2011). A case study of applying Kano's model and ANOVA technique in evaluating service quality. Information Technology Journal, 10(1), 89-97. https://doi.org/10.3923/itj.2011.89.97

Lajevardi, M., Fakharmanesh, S., Emami, J., \& Lajevardi, M. (2012). An applied marketing model for university students' satisfaction. Australian Journal of Business and Management Research, 2(9), 1-12.

Lee, Y.C., Lin, S.B., \& Wang, Y.L. (2011). A new Kano's evaluation sheet. The TQM Journal, 23(2), 179-195. https://doi.org/10.1108/17542731111110230

Lin, C.N., Tsai, L.F., Wang, P.W., Su, W.J., \& Shaw, J.C. (2011). Using the Kano two-dimensional quality model to evaluate service quality of resort hotels. International Journal of Computer Science and Network Security, 11(5), 84-87.

Lin, H.S., Hsieh, L.Y., \& Huang, C.C. (2012). Applying Kano's Model to Analyze the Tourism Region of the Public Transportation Service Quality--Liujia Railway Station to Neiwan Scenic Area Case Study. Advances in Information Sciences \& Service Sciences, 4(19), 116.

Löfgren, M., \& Witell, L. (2005). Kano’s theory of attractive quality and packaging. Quality Management Journal, 12(3), 7-20. https://doi.org/10.1080/10686967.2005.11919257

Löfgren, M., Witell, L., \& Gustafsson, A. (2011). Theory of attractive quality and life cycles of quality attributes. The TQM Journal, 23(2), 235-246. https://doi.org/10.1108/17542731111110267

Marsillac, E., \& Roh, J.J. (2014). Connecting product design, process and supply chain decisions to strengthen global supply chain capabilities. International Journal of Production Economics, 147B, 317-329. https://doi.org/10.1016/j.ijpe.2013.04.011

Mikulić, J., \& Prebežac, D. (2011). A critical review of techniques for classifying quality attributes in the Kano model. Managing Service Quality: An International Journal, 21(1), 46-66. https:/ / doi.org/10.1108/09604521111100243

Modaresi, S., \& Mehrara, A. (2014). Comparative Study of Customers' Satisfaction at Governmental \& Private Banks. Nationalpark-Forschung in der Schweiz. (Switzerland Research Park Journal), 103(1).

Momani, A., Al-Hawari, T., Al-Shebami, H., \& Al-Araidah, O. (2014). Classifying and Ranking Healthcare Quality Attributes Using Integrated Kano-Fuzzy Analytical Hierarchy Process Model. Engineering Management Research, 3(1), 68-88. https://doi.org/10.5539/emr.v3n1p68

Nilsson-Witell, L., \& Fundin, A. (2005). Dynamics of service attributes: a test of Kano's theory of attractive quality. International Journal of Service Industry Management, 16(2), 152-168. https://doi.org/10.1108/09564230510592289

Potra, S.A., Izvercian, M., Pugna, A.P., \& Dahlgaard, J.J. (2017). The HWWP, a refined IVA-Kano model for designing new delightful products or services. Total Quality Management \& Business Excellence, 28(1-2), 104-117. https://doi.org/10.1080/14783363.2015.1050168

Raharjo, H., Brombacher, A.C., Goh, T.N., \& Bergman, B. (2010). On integrating Kano's model dynamics into QFD for multiple product design. Quality and Reliability Engineering International, 26(4), 351-363.

Redfern, R., \& Davey, C.L. (2003). Supply chain market orientation in new product development in the UK: A pilot case study. Journal of Fashion Marketing and Management: An International Journal, 7(1), 65-77. https://doi.org/10.1108/13612020310464377

Regattieri, A., Santarelli, G., \& Olsson, A. (2012). The Customers' Perception of Primary Packaging: a Comparison between Italian and Swedish Situations. In Proceedings of the 18th LAPRI World Packaging Conference. 
Seyedi, S.M., Shirazifar, M., Dalvand, M.R., \& Zohdi, M.H. (2012). Optimal examination and prioritization of the factors affecting customers' satisfaction using integrated Quality Function Deployment (QFD) and Kano's model: Case study of Shiraz's Refah bank. African Journal of Business Management, 6(35), 9762-9772.

Sohn, J.I., Woo, S.H., \& Kim, T.W. (2017). Assessment of logistics service quality using the Kano model in a logistics triadic relationship. International Journal of Logistics Management, 28(2), 680-698.

https://doi.org/10.1108/IJLM-09-2015-0172

Strandberg, C., Wahlberg, O., \& Öhman, P. (2012). Challenges in serving the mass affluent segment: Bank customer perceptions of service quality. Managing Service Quality: An International Journal, 22(4), 359-385.

https://doi.org/10.1108/09604521211253478

Sukwadi, R., Yang, C.C., \& Liu, F. (2011). Towards an identification and classification of service quality attributes in higher education. International Journal of e-Education, e-Business, e-Management and e-Learning, 1(2), 163-168.

https://doi.org/10.7763/IJEEEE.2011.V1.26

Tang, L.L., \& Huang, S.L. (2004). A two-dimensional quality model for evaluating the quality attributes of notebook computers. Asia Pacific Management Review, 9(3), 539-555.

Tontini, G., \& Picolo, J.D. (2013). Identifying the impact of incremental innovations on customer satisfaction using a fusion method between importance-performance analysis and Kano model. International Journal of Quality \& Reliability Management, 31(1), 32-52. https:// doi.org/10.1108/IJQRM-05-2012-0062

Violante, M.G., \& Vezzetti, E. (2014). A methodology for supporting requirement management tools (RMt) design in the PLM scenario: an user-based strategy. Computers in Industry, 65(7), 1065-1075.

https://doi.org/10.1016/j.compind.2014.05.001

Violante, M.G., \& Vezzetti, E. (2015). Virtual interactive e-learning application: An evaluation of the student satisfaction. Computer Applications in Engineering Education, 23(1), 72-91. https://doi.org/10.1002/cae.21580

Violante, M.G., \& Vezzetti, E. (2017). Kano qualitative vs quantitative approaches: An assessment framework for products attributes analysis. Computers in Industry, 86, 15-25. https://doi.org/10.1016/j.compind.2016.12.007

Walden, D. (1993). Kano's Methods for Understanding Customer-defined Quality. Center for Quality Management Journal, 2(4), 3-36.

Wang, T., \& Ji, P. (2010). Understanding customer needs through quantitative analysis of Kano's model. International Journal of Quality \& Reliability Management, 27(2), 173-184. https://doi.org/10.1108/02656711011014294

Witell, L., Löfgren, M., \& Dahlgaard, J.J. (2013). Theory of attractive quality and the Kano methodology-the past, the present, and the future. Total Quality Management \& Business Excellence, 24(11-12), 1241-1252. https://doi.org/10.1080/14783363.2013.791117

Wu, M., \& Wang, L. (2012). A continuous fuzzy Kano's model for customer requirements analysis in product development. Proceedings of the Institution of Mechanical Engineers, Part B: Journal of Engineering Manufacture, 226(3), 535-546. https://doi.org/10.1177/0954405411414998

Xu, Q., Jiao, R. J., Yang, X., Helander, M., Khalid, H.M., \& Opperud, A. (2009). An analytical Kano model for customer need analysis. Design Studies, 30(1), 87-110. https://doi.org/10.1016/j.destud.2008.07.001

Yang, C.C., Jou, Y.T., \& Cheng, L.Y. (2011). Using integrated quality assessment for hotel service quality. Quality \& Quantity, 45(2), 349-364. https://doi.org/10.1007/s11135-009-9301-4

Zarei, A., Hemati, M., \& Rafeeian, M. (2012). Prioritizing the effective factors for customers attraction: A case study of Sepah Bank. Management Science Letters, 2(3), 961-970. https://doi.org/10.5267/j.msl.2012.01.020

Żemła, M. (2008). The product quality of Polish ski-resorts: A case study of Silesian skiers' requirements, satisfaction and complaints. Turizam: żanstveno-stručni časopis, 56(1), 41-58.

Zhang, P., \& von Dran, G.M. (2001). User Expectations and Rankings of Quality Factors in Different Web Site Domains. International Journal of Electronic Commerce, 6(2), 9-33. https://doi.org/10.1080/10864415.2001.11044237 
Zhifeng, Z., (2007). Web site \& customer value: from a marketing perspective. Master dissertation. Kristianstad University College, Sweden.

\author{
Journal of Industrial Engineering and Management, 2018 (www.jiem.org)
}

\title{
(1) (1) (
}

Article's contents are provided on an Attribution-Non Commercial 4.0 Creative commons International License. Readers are allowed to copy, distribute and communicate article's contents, provided the author's and Journal of Industrial Engineering and Management's names are included. It must not be used for commercial purposes. To see the complete license contents, please visit https://creativecommons.org/licenses/by-nc/4.0/. 